\title{
Morfodinâmica da foz do Arroio Carahá em laguna costeira micromaré (Lagoa dos Patos, sul do Brasil)
}

\author{
Natália LEMKE'] Lauro Julio CALLIARI², José Antônio Scotti FONTOURA ${ }^{3}$, \\ Christian Garcia SERPA ${ }^{3}$ \& Marine Jusiane Bastos da SILVA ${ }^{4}$ \\ 1 Instituto de Matemática, Estatística e Física, Universidade Federal do Rio Grande. Av. Itália Km 8 , \\ CEP 96.203-000, Rio Grande, RS, Brasil (natalialemke@gmail.com). \\ 2 Instituto de Oceanografia, Universidade Federal do Rio Grande. Av. Itália Km 8, CEP 96.203-000, Rio \\ Grande, RS, Brasil (Icalliari@log.furg.br) \\ ${ }^{3}$ Escola de Engenharia, Universidade Federal do Rio Grande. Av. Itália Km 8, CEP 96.203-000, Rio Grande, \\ RS, Brasil (scottifontoura@gmail.com, christianserpa@gmail.com). \\ ${ }^{4}$ Instituto de Geociências, Universidade Federal do Rio Grande do Sul. Av. Bento Gonçalves, 9.500, CEP. \\ 91.540-000, Porto Alegre, RS, Brasil (marinebsilva@gmail.com).
}

\begin{abstract}
Resumo. O Arroio Carahá desemboca em uma enseada na margem oeste da Lagoa dos Patos, onde se observa a formação de uma barra arenosa que inviabiliza a navegação de barcos pesqueiros de pequeno porte pelo canal. O objetivo deste estudo é investigar os processos lagunares que envolvem o fechamento da foz do Arroio Carahá, e as condições naturais que permitem o passe sobre a barra. Através do georreferenciamento e da análise de imagens aéreas e de satélite de 1953, 1977 e 2010, foi realizado o estudo do comportamento da linha de costa, que indicou um acentuado processo de retração na margem ao norte da foz do arroio, com taxa média de 1,1 m/ano, e progradação na margem ao sul, com taxa média de 0,2 m/ ano. Através da obtenção e tratamento de dados hidrodinâmicos e morfológicos da região, foi realizada a simulação dos processos dinâmicos na enseada com o software de modelagem numérica Delft-3D, utilizando os módulos de morfologia, hidrodinâmico e de ondas acoplados. Houve formação de uma zona de convergência de correntes (NE e SO) na região central da enseada, resultando no desenvolvimento da barra arenosa na foz do Arroio Carahá. As taxas médias de transporte sedimentar nos perfis da foz, ao norte e ao sul, atingiram $7,3 \mathrm{~m}^{3} / \mathrm{ano} / \mathrm{m}$, $9 \mathrm{~m}^{3} / \mathrm{ano} / \mathrm{m}$ e $6,7 \mathrm{~m}^{3} / \mathrm{ano} / \mathrm{m}$, respectivamente, com predominância de transporte líquido para o sul. Após a formação da barra arenosa na foz e seu consequente fechamento, as condições de baixa energia hidrodinâmica da enseada e do canal não permitiram remobilizar os sedimentos depositados. Diante estes processos morfodinâmicos, a condição natural que poderá viabilizar a passagem de pequenas embarcações pelo canal está associada à elevação do nível d'água da laguna (condições de cheias).
\end{abstract}

Palavras-chave. praias arenosas, variação da linha de costa, barra arenosa, morfodinâmica lagunar.

\begin{abstract}
MORPHOdYNAMICS OF THE MOUTH OF THE CARAHÁ CREEK IN MICROTIDAL COASTAL LAGOON (LAGOA DOS PATOS, SOUTHERN BRAZIL). The Carahá Creek flows into a bay on the western margin of the Lagoa dos Patos, where there is a sandy shoal that hinders navigation of small fishing boats through the channel. This study aims at investigating lagoonal processes that have led to the closure of the mouth of the Carahá Creek and natural conditions that allow the pass over the bar. Georeferencing and the analysis of aerial and satellite images from 1953, 1977 and 2010 enabled to carry out the study of the coastline behavior, which showed an accentuated retraction process on the northern margin of its mouth (mean rate was 1.1 m.year-1) and progradation on its southern margin (mean rate was 0.2 m.year-1). Hydrodynamic and morphological data on the region were collected and processed to carry out the simulation of dynamic processes in the bay by the Delft-3D numerical modeling software program, using coupled morphology, hydrodynamic and wave modules. A convergence zone of currents (NE and SW) formed in the central region of the bay and resulted in the development of the sandy bar in the mouth of the Carahá Creek. Mean rates of sediment transport in the mouth itself and both north and south of the mouth of the creek reached $7.3,9$ and $6.7 \mathrm{~m}^{3}$.year-1.m-1, respectively, with predominance of liquid transport to the south. After the formation of the sandy bar in the mouth and its consequent closure, low hydrodynamic energy conditions in the bay and channel did not allow deposited
\end{abstract}


sediments to be remobilized. In view of these morphodynamic processes, the natural condition that may enable small vessels to pass through the channel is associated with the water level rise in the Lagoa dos Patos (flood conditions).

Keywords. sandy beaches, coastline changes, sandy shoal, lagoon morphodynamics.

\section{Introdução}

Desembocaduras são os ambientes mais complexos em zonas costeiras devido aos processos de interação entre ondas, correntes, transportes de sedimentos e morfologia (Komar, 1996). A entrada da energia de ondas e correntes no sistema induz a dinâmica dos fluidos, que é influenciada pela topografia, interagindo assim com o transporte de sedimentos. Gradientes no transporte de sedimentos resultam em regiões de erosão e deposição, modificando a morfologia e, consequentemente, a hidrodinâmica, possibilitando novas alterações morfológicas (Cassiano \& Siegle, 2010). A dinâmica costeira atua tanto na formação, quanto no processo de equilíbrio destas feições.

Diversos fatores são responsáveis pela estabilidade de uma desembocadura, como: geometria do canal, ondas, correntes, marés, fonte de sedimentos, estratigrafia regional, declividade do ambiente, batimetria e obras de engenharia costeira (Fitzgerald et al., 2000). A incidência oblíqua de ondas com a formação de correntes longitudinais resulta no transporte de sedimentos paralelo à costa, processo eficientena migração de canais. Dependendo da quantidade de sedimentos disponíveis e das condições de energia do ambiente costeiro, poderá ocorrer a formação de bancos, fechando a entrada do canal (Bruun, 1995). O conhecimento da morfologia de fundo nas adjacências de desembocaduras é fundamental para estudos hidrodinâmicos associados a modelos numéricos, especialmente aqueles que visam segurança à navegação (Goulart \& Calliari, 2011). Estudos sobre processos de erosão, progradação e estabilidade da linha de costa também são necessários para a compreensão da dinâmica atuante em regiões costeiras e lagunares.

Na Lagoa dos Patos, sul do Brasil - RS, estudos sobre morfodinâmica mostraram processos de erosão, progradação e estabilidade em diferentes regiões. Estudos de variação da linha de costa foram realizados para as praias do Saco do Laranjal (Fischer \& Calliari, 2011), praia do Barro Duro (Ferreira, 2017), desembocadura do Canal São Gonçalo e margens adjacentes (Ambrosi, 2018), margem do Canal de Acesso ao Porto do Rio Grande (Lima, 2018) e arcos praiais entre os esporões Dona Helena, Dona Maria e Vitoriano (Miranda et al., 2019). Estudos do comportamento morfodinâmico com modelo numérico Delft-3D foram realizados para a porção sul da margem oeste do Canal de acesso ao Porto do Rio Grande, entre o cais do Terminal de Container TECON e a raiz do molhe oeste (Lima et al., 2019), e para os arcos praias entre os esporões Dona Helena, Dona Maria e Vitoriano (Miranda, 2020). Estes estudos contribuem de forma significativa para a compreensão dos processos dinâmicos atuantes na laguna, e do comportamento morfodinâmico de suas margens e seus tributários.

Vários corpos hídricos desembocam na Lagoa dos Patos favorecendo o acesso à laguna, com importância tanto na forma de interiorizar a navegação lagunar, como também na constituição de portos comerciais e recreacionais. Na margem oeste da Lagoa dos Patos desembocam o Canal São Gonçalo (que a interliga à Lagoa Mirim), o Arroio São Lourenço, o Arroio Carahá, o rio Camaquã e os rios do complexo Guaíba: Jacuí, Caí, Sinos e Gravataí. Na margem leste, através do Canal do Rio Grande há o acesso ao Oceano Atlântico. O desenvolvimento urbano e a consequente ocupação nas áreas próximas a desembocaduras fluviais, tanto de grande quanto pequeno porte, conferem uma maior importância em estudos de gerenciamento costeiro, no intuito de manter fixas estas feições, visando o acesso de embarcações em qualquer período do ano.

O Arroio Carahá localiza-se no município de São Lourenço do Sul e deságua em uma enseada na margem oeste da Lagoa dos Patos (Fig. 1), onde se observa a formação de uma barra arenosa que inviabiliza a navegação de barcos pesqueiros de 
pequeno porte pelo canal. Diversos estudos são necessários para a compreensão dos processos dinâmicos responsáveis pelo fechamento do canal com a formação da barra arenosa, como: incidência e propagação de ondas da laguna, hidrodinâmica do arroio e da enseada, transporte sedimentar e morfologia.

Diante do exposto, o objetivo deste estudo é investigar os processos lagunares que envolvem o fechamento da foz do Arroio Carahá, a partir da caracterização da evolução morfológica da região, e as condições naturais que permitem o passe sobre a barra arenosa formada na sua foz.

\section{2 Área, material e métodos}

\section{1 Área de estudo}

A Lagoa dos Patos é a maior laguna costeira do país, com aproximadamente 250 $\mathrm{km}$ de comprimento, largura média de $40 \mathrm{~km}$, e profundidade média de 5 m (Castelão \& Möller Jr., 2003). Possui orientação geral NE-SO e em sua maior parte é protegida do Oceano Atlântico por um sistema de barreiras arenosas que se estende do norte da laguna até o extremo sul, onde há comunicação com o oceano, através do Canal do Rio Grande (Toldo Jr., 1991). A maré e as oscilações de longo período originadas no oceano são filtradas na região do canal de acesso à Lagoa dos Patos (Möller Jr. et al., 2001). Apresenta regime de micromaré, com amplitude média de maré astronômica de 0,47 m na região do Rio Grande (Martins et al.,1989).

o conhecimento e a compreensão da hidrodinâmica, das ondas, da morfologia e do transporte de sedimentos na Lagoa dos Patos são fundamentais para o estudo da morfodinâmica da enseada de São Lourenço do Sul, onde o Arroio Carahá desemboca.

A hidrodinâmica da Lagoa dos Patos depende principalmente das relações entre descargas fluviais e ventos (Möller Jr., 1996). Suas margens são formadas por esporões arenosos associados aos ventos bidirecionais (NE-SO), ao regime de micromaré e ao transporte sedimentar resultante da incidência oblíqua de ondas por refração (Zenkovitch, 1959).
O regime ondulatório da Lagoa dos Patos é caracterizado por curtos períodos de pico (Tp) e pequenos valores de altura significativa $(\mathrm{Hs})$ devido à profundidade rasa da laguna. Dados de ondas de janeiro a junho de 2015 obtidos pelo ondógrafo direcional Waverider (pertencente à FURG por meio do projeto Rede Ondas), fundeado no ponto de coordenadas 412.749,08 m E e 6.516.280,54 m N, UTM 22S (Fig. 1C), local onde a profundidade é cerca de $6 \mathrm{~m}$, correspondem às maiores frequências de Hs de até 0,3 m $(41,2 \%)$ e de 0,3 m a 0,6 m (38\%), Tp de 2,5 s a 3 s (25,6\%) e de $3 \mathrm{~s}$ a 3,5 s (22,1\%) e direção de pico (Dp) de $\mathrm{E}$ (33,3\%) (Lemke et al., 2017a). Dados de ondas de agosto a dezembro de 2018 obtidos pelo segundo ondógrafo direcional adquirido pela FURG por meio do projeto Rede Ondas, fundeado no mesmo local, correspondem às maiores frequências de Hs de até $0,3 \mathrm{~m}(43,7 \%)$ e de $0,3 \mathrm{~m}$ a 0,6 m (36,6\%), Tp de 3 s a 4 s (41\%) e de 2 s a 3 s (37,9\%) e Dp de ENE (Marinho et al., 2020). Especificamente para as estações do ano, os valores médios de Hs e períodos nas proximidades de São Lourenço do Sul são, respectivamente, 0,6 m e 3,1 s no verão, 0,5 m e 2,8 s no outono, 0,5 m e 2,7 s no inverno, 0,6 m e 3,0 s na primavera (Toldo Jr. et al., 2006). Embora a pista de ventos predominantes (NE) seja ampla, as ondas são atenuadas pela presença dos esporões arenosos na Lagoa dos Patos (Simão, 2016). Os esporões, juntamente com a orientação da linha de costa, influenciam nos campos de ondas através dos processos de formação de zonas de sombra devido aos esporões emersos, assim como das transformações de ondas em águas rasas (refração e dissipação) na passagem pelo extenso banco submerso raso dos esporões; sendo que os esporões submersos atenuam as ondas, com taxas entre 18\% e $46 \%$ ao longo das porções longitudinais dos esporões (Miranda et al., 2020).

A Lagoa dos Patos apresenta duas distintas regiões morfológicas e sedimentológicas: a margem interna, entre a linha de costa e a isóbata de 5 metros; e o piso lagunar que corresponde a um fundo plano na área interna à isóbata de 5 metros (Toldo Jr., 1991). A margem interna é predominantemente arenosa, enquanto que o 
piso lagunar é predominantemente lamoso (Toldo Jr. et al., 2006). Na margem oeste os sedimentos são pobremente selecionados, com tamanhos entre areia fina e cascalho; na margem leste são bem selecionados, com predominância de areia fina. A margem oeste apresenta inclinações de aproximadamente 1/500; já a margem leste, em torno de 1/200 (Martins et al., 1989).
O transporte longitudinal ao longo da margem leste da Lagoa dos Patos indica que sedimentos são erodidos e transportados em direção ao interior do corpo lagunar, enquanto que ao longo da margem oeste os sedimentos geralmente são movidos em direção à linha de costa; a deriva litorânea é predominantemente para o norte na margem leste, e para o sul na margem oeste (Toldo Jr. et al., 2003).
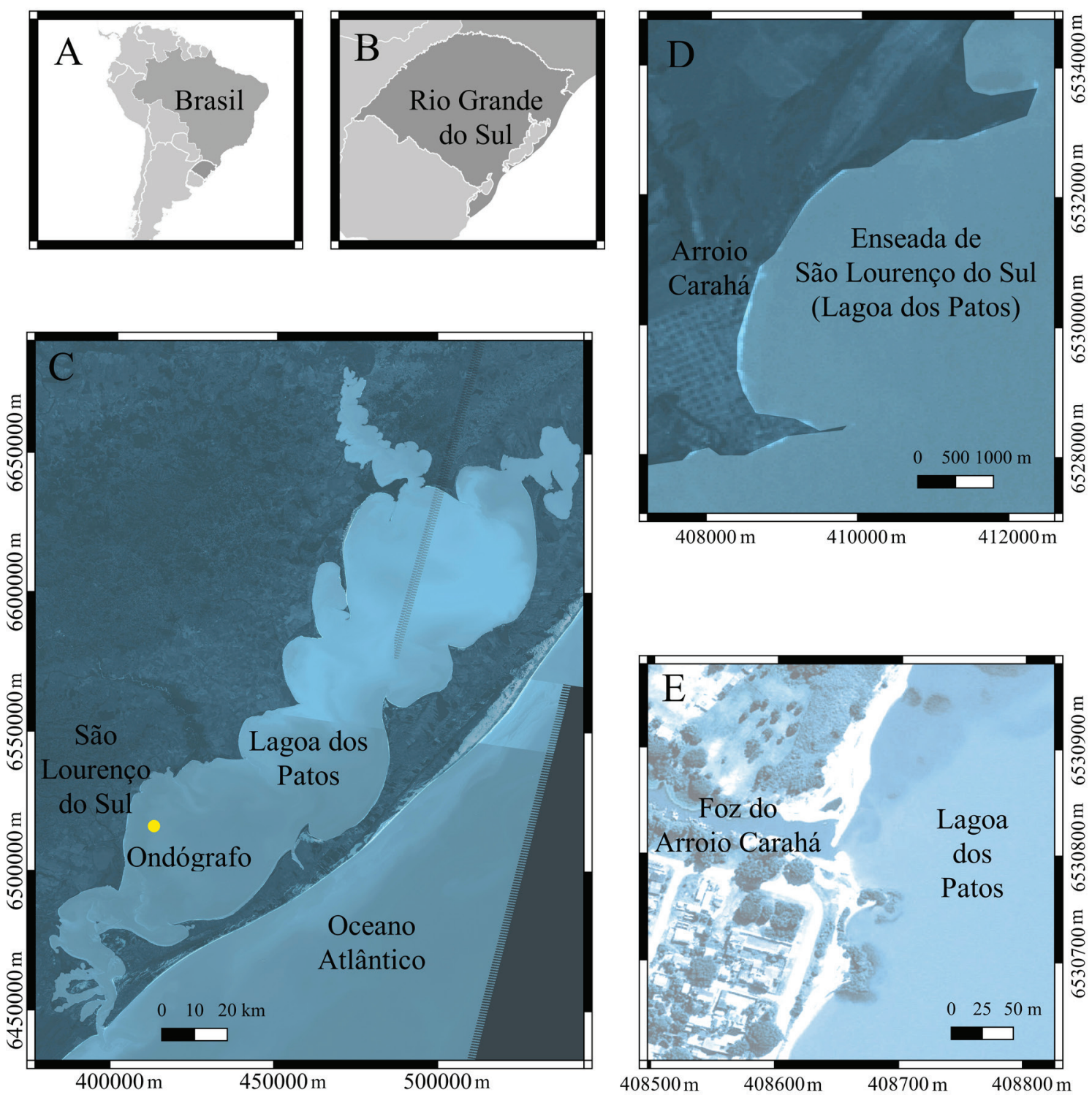

Base cartográfica: IBGE Imagens: LandSat 8 (USGS) e Google Earth Pro

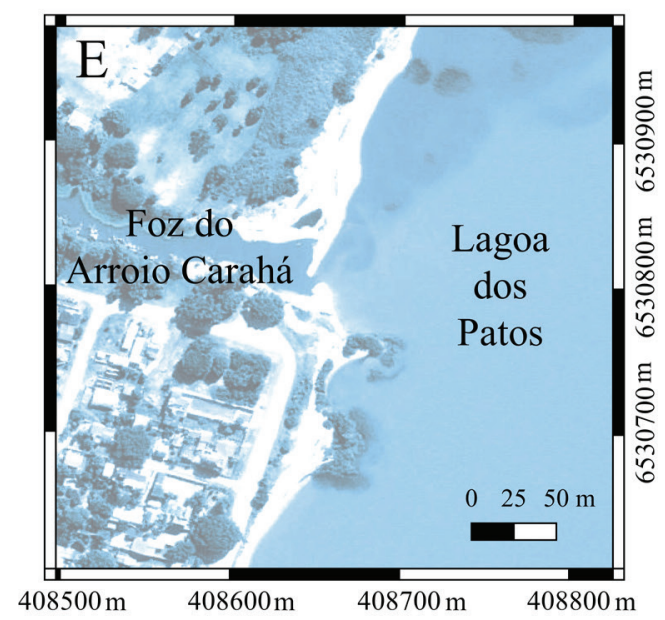

Datum: WGS - 84 Projeção: UTM - 22S

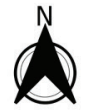

Figura 1. Localização da área de estudo. A) Brasil; B) Rio Grande do Sul; C) Lagoa dos Patos e localização do ondógrafo direcional Waverider; D) Enseada de São Lourenço do Sul; E) Foz do Arroio Carahá.

Figure 1. Location of the study area. A) Brazil; B) Rio Grande do Sul; C) Lagoa dos Patos and location of the Waverider directional buoy; D) São Lourenço do Sul Bay; E) Mouth of the Carahá Creek. 


\subsection{Material e métodos}

A metodologia desenvolvida nesta pesquisa abrange o estudo da variação temporal da linha de costa, a partir da análise de imagens aéreas e de satélite georreferenciadas, assim como a modelagem morfodinâmica, através do software Delft-3D, realizada com dados hidrodinâmicos e morfológicos da região.

\subsubsection{Variação da linha de costa}

Com intuito de realizar uma análise histórica do comportamento da linha de costa foram utilizadas fotografias aéreas da região de interesse referentes aos anos de 1953 (escala 1:40.000) e 1977 (escala 1:8.000), disponibilizadas pela Agência da Lagoa Mirim (ALM) - Pelotas (RS), e uma imagem de sensor orbital a bordo de satélite do ano de 2010, adquirida através do Google Earth Pro. O critério adotado foi a análise do comportamento natural da linha de costa. Portanto, não foram utilizadas imagens de satélite posteriores ao ano de 2010, visto que houve uma obra de engordamento de praia na margem sul da enseada após a enchente ocorrida em 2011, em função de um evento extremo de intensa precipitação que ocorreu na Bacia Hidrográfica do Arroio São Lourenço (outro arroio do município), adjacente à Bacia Hidrográfica do Arroio Carahá.

Para o georreferenciamento das imagens foram coletadas coordenadas geográficas de 50 pontos de controle pré-selecionados no município de São Lourenço do Sul utilizando um equipamento GNSS Geodésico da marca Leica, modelo GS15. Este equipamento operou no modo de posicionamento relativo "stop and go", com correções cinemáticas em tempo real (RTK) em relação a uma base conhecida, e foi configurado para gravar somente dados de pontos em que o erro máximo em três dimensões (3DCQ) fosse menor que $2 \mathrm{~cm}$. 0 datum de referência adotado foi o WGS 84 e o sistema de projeção, UTM, zona 22 S. Para o posicionamento relativo, um sensor GNSS (base) foi instalado em uma referência de nível (RN) da cidade e outro sensor GNSS (móvel) foi utilizado para coletar coordenadas geográficas de 50 pontos de controle pré-selecionados, em locais com construções existentes desde o ano de 1953

Um dos geoindicadores para interface entre areia e água apresentados por Boak \& Turner (2005) é a linha d'água instantânea. Como as fotografias aéreas mais antigas (1953 e 1977) estão em gradientes de cinza e com escalas pequenas, foi adotada a posição da linha d'água como geoindicador, assim como utilizado por Fischer \& Calliari (2011), Ferreira (2017), Ambrosi (2018) e Lima (2018) em estudos para a Lagoa dos Patos. Com as imagens georreferenciadas, foi feita a vetorização da linha de costa no software AutoCad-2014, conforme metodologia de Fischer \& Calliari (2011). A partir de uma linha auxiliar, paralela à costa, foram traçados perfis perpendiculares em intervalos de 50 metros, que serviram de base para medir as distâncias entre as posições da linha de costa nos diferentes anos. Variações negativas indicaram recuo da linha de costa, enquanto que variações positivas, progradação da linha de costa.

$O$ erro de amostragem foi determinado a partir da metodologia utilizada por Lélis \& Calliari (2006) e Fischer \& Calliari (2011), que consiste em medir a distância entre dois pontos conhecidos, tanto em campo, quanto digitalmente nas imagens georreferenciadas, para posteriormente comparar estes dados. O valor da distância entre os dois pontos conhecidos foi denominado de $L$. Portanto, foram obtidos quatro valores para $L$, um medido em campo e os outros três medidos no software AutoCad-2014 em cada uma das imagens georreferenciadas (1953, 1977 e 2010). A diferença entre a distância em cada imagem e a distância em campo corresponde ao erro de posicionamento para cada imagem.

A tabela 1 apresenta os valores medidos em campo e os valores medidos nas imagens, indicados por $L$, assim como os respectivos erros, onde se observa que o maior erro ocorreu na aferição com a aerofotografia mais antiga (ano de 1953), com valor de 0,94 m. Desta forma, medições de variação da linha de costa com valores menores que 1,0 m foram desconsideradas. 
Tabela 1. Erros de amostragem obtidos na confecção dos mosaicos.

Table 1. Sampling errors found throughout mosaic making.

\begin{tabular}{ccc}
\hline Local de medição & L (m) & Erro (m) \\
\hline Imagem de 1953 & 111,35 & 0,94 \\
Imagem de 1977 & 111,24 & 0,83 \\
Imagem de 2010 & 110,60 & 0,19 \\
Em campo & 110,41 & - \\
\hline
\end{tabular}

\subsubsection{Simulação do comportamento morfodinâmico}

A análise do comportamento morfodinâmico foi feita a partir da aquisição e tratamento de dados hidrodinâmicos e morfológicos da região de estudo e da modelagem numérica com o software Delft-3D, modelo desenvolvido em Delft, Holanda, pela empresa Deltares em cooperação com Delft University of Technology (TU Delft).

O Delft-3D é constituído por um sistema de modelos numéricos em duas e em três dimensões (2D e 3D) com vários módulos que visam a simulação de processos costeiros, tais como geração e propagação de ondas, hidrodinâmica, transporte de sedimentos e mudanças morfológicas. O módulo de morfologia integrado ao módulo hidrodinâmico realiza alterações na batimetria a cada passo de tempo. Quando acoplado com o modelo de ondas calcula os processos de interação onda-corrente, integrando os efeitos de ondas, correntes e transporte de sedimentos no desenvolvimento morfológico. O modelo de morfologia é executado dentro do modelo hidrodinâmico; durante o processo de simulação simultânea (interface Online Wave) de transporte de sedimentos e variações morfológicas, a cada passo de tempo são consideradas as mudanças na batimetria (Lesser et al., 2004).

0 modelo numérico Delft-3D tem sido utilizado em estudos abrangendo a região da Lagoa dos Patos, tais como: Vinzon et al. (2009), Simão (2016), Lemke et al. (2017b), Lemke et al. (2018), Lima et al. (2018), Miranda et al. (2020), Miranda (2020) e Marinho et al. (2020).

No presente estudo foram utilizados os módulos hidrodinâmico (FLOW), de ondas (SWAN) e de morfologia (MOR) acoplados.
Batimetria

Dados batimétricos da enseada de São Lourenço do Sul foram obtidos a partir de um levantamento detalhado realizado com uma ecossonda da marca Lowrance $\odot$ (modelo LCX19C) de dupla frequência $200 / 50 \mathrm{kHz}$ e com precisão vertical de 10 centímetros (Fig. 2A). Complementarmente, dados batimétricos da Lagoa dos Patos foram digitalizados a partir de cartas náuticas disponibilizadas no banco de dados da Diretoria de Hidrografia e Navegação da Marinha do Brasil (DHN). Após o tratamento dos dados batimétricos, foi realizada a interpolação triangular na grade numérica retangular construída no software Delft-3D para a enseada de São Lourenço do Sul, com largura de 4,7 km e comprimento de $9,7 \mathrm{~km}$, composta por 58.056 nós e rotacionada a $30^{\circ}$ no sentido horário a partir do eixo norte, seguindo a orientação geral da linha de costa (Fig. 2B).

Devido ao tempo de processamento para a modelagem morfodinâmica, a grade foi refinada na região de maior interesse, ou seja, nas proximidades da foz do Arroio Carahá. Os maiores espaçamentos entre os nós da grade são de 50 metros e aparecem nos contornos da grade. Quanto mais próximo da foz, os espaçamentos entre os nós tornam-se menores, chegando a 16 metros na região de maior refinamento.

\section{Granulometria}

Para determinar a composição sedimentológica da porção subaquosa e o tamanho mediano do grão $\left(D_{50}\right)$, foram coletadas amostras de sedimentos com um amostrador do tipo Van Veen. Foram coletadas 28 amostras, sendo 21 na enseada de São Lourenço do Sul, 4 no canal do Arroio Carahá e 3 na barra arenosa formada na foz (Fig. 3). Com as amostras devidamente identificadas foram realizados 


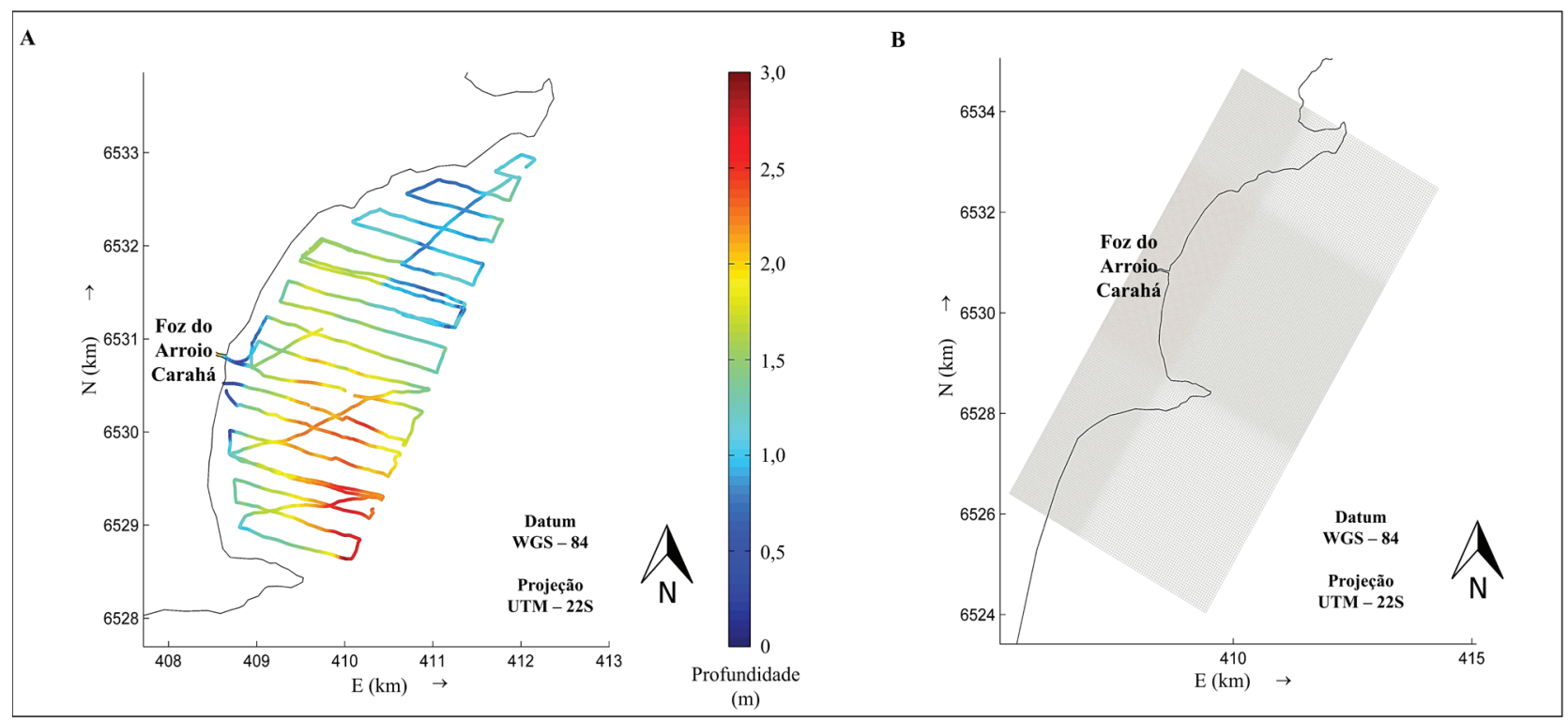

Figura 2. Batimetria e grade numérica da enseada de São Lourenço do Sul. A) Levantamento batimétrico realizado com a ecossonda na enseada de São Lourenço do Sul; B) Grade numérica (4,7 km de largura, 9,7 km de comprimento, 58.056 nós).

Figure 2. Bathymetry and numerical grid of the São Lourenço do Sul Bay. A) Bathymetric survey carried out by an echosounder in the São Lourenço do Sul Bay; B) Numerical grid (4.7 km wide, 9.7 km long, 58,056 knots).

os procedimentos convencionais (lavagem e secagem) para a análise granulométrica. Para os sedimentos grossos, constituídos por partículas maiores que 0,062 mm (menores que 4 $\phi$ ) de diâmetro, foi realizado o peneiramento mecânico em intervalos de $1 / 4 \phi$, conforme a escala de Wentworth de 1922 (Suguio, 1973). Para os sedimentos finos, caracterizados por partículas menores que 0,062 mm (maiores que $4 \phi$ ) de diâmetro, foi realizado o método da pipetagem. Após, com o software de análise estatística textural SysGran-3, foram determinados os valores de diâmetro mediano do grão $\left(D_{50}\right)$ para cada amostra de sedimentos, conforme Camargo (2006).

\section{Nível d'água}

Através do banco de dados da Agência Nacional de Águas (ANA, 2020) foram obtidos dados de nível d'água de 1985 até 2019 medidos no ponto de coordenadas 408.818,52 m E e 6.528.129,80 m N, UTM 22S (Fig. 3), situado na Praia das Nereidas em São Lourenço do Sul, local de medição mais próximo da região de estudo. Com estes dados foi determinado o nível d'água médio para todo período, assim como para cada estação do ano, com intuito de verificar a influência da variação sazonal de nível nas condições da navegabilidade de pequenas embarcações sobre a barra arenosa.

\section{Vazão do Arroio Carahá}

Para determinar a vazão média do Arroio Carahá, foi adotado o método convencional de Santos et al. (2001), que emprega a medição e a integração da distribuição de velocidades na seção transversal do rio. Foi utilizado um molinete hidrométrico da marca Hidromec, que possui uma hélice que executa determinado número de rotações por segundo em função do escoamento do rio. As medições foram feitas na seção transversal delimitada por uma ponte situada próxima à foz do Arroio Carahá (no ponto de coordenadas 408.221,00 m E e 6.530.506,26 m N, UTM 22S - Fig. 3), onde a largura do arroio é cerca de 25 metros e a profundidade média é de 3 metros. As medições foram feitas em quatro datas em diferentes períodos, sendo que a última corresponde ao final do período de quatro dias de precipitação, com o total de 59,7 $\mathrm{mm}$. Foram analisados dados de precipitação da Bacia Hidrográfica do Arroio Carahá dos anos de 1966 a 2019, medidos no ponto de coordenadas 397.196,31 m E e 6.538.863,25 m N, UTM 22S, 


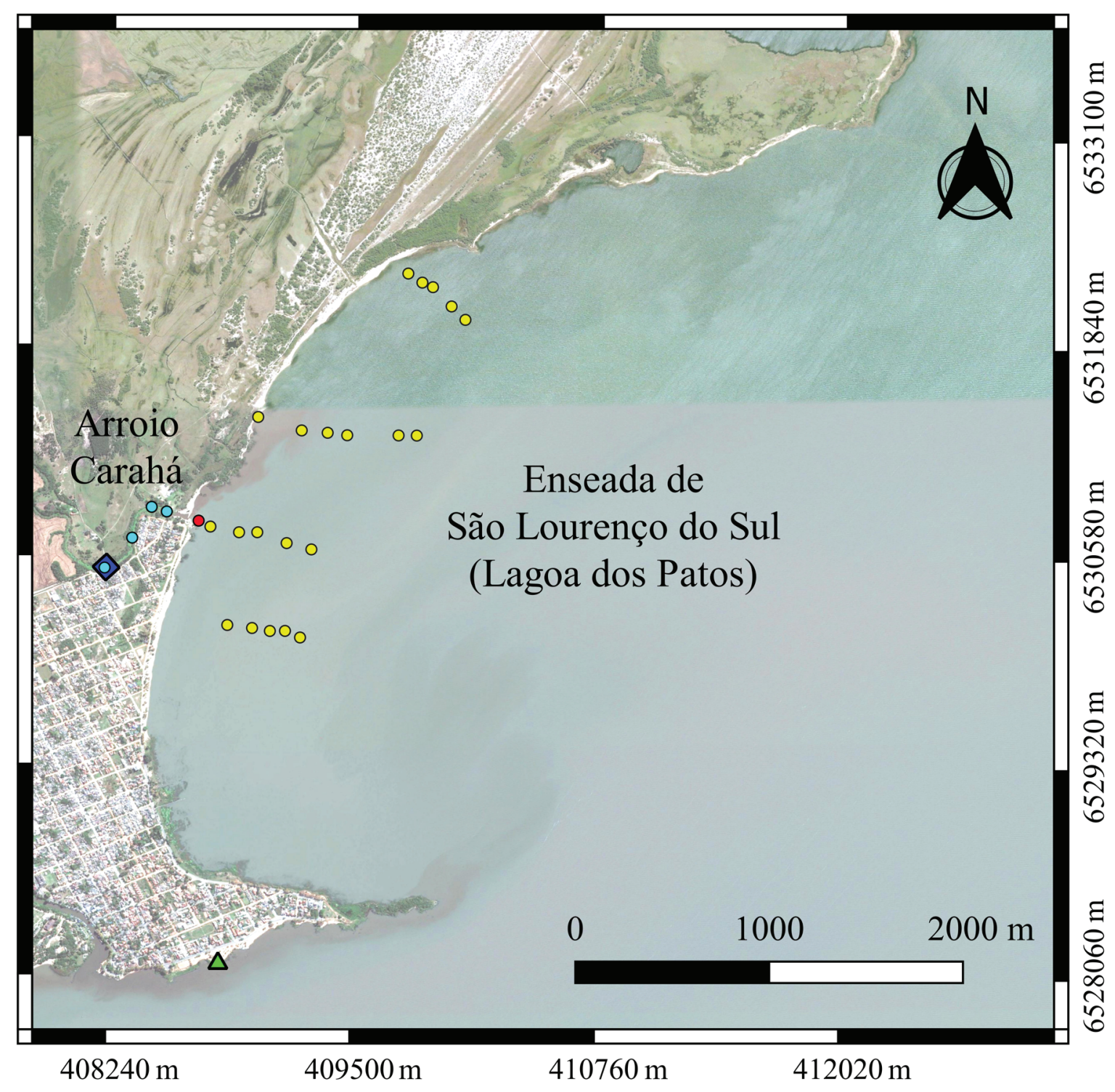

Imagem: Google Earth Pro

Datum: WGS - 84

Projeção: UTM - 22S

\section{Legenda}

- Amostras de sedimentos da enseada

- Amostras de sedimentos do canal

- Amostras de sedimentos da barra

$\Delta$ Linígrafo

Molinete

Figura 3. Mapa de localização dos pontos de coleta de dados. Localização das amostras de sedimentos (canal, barra arenosa e enseada), do linígrafo (dados de nível d'água da Lagoa dos Patos) e do ponto de medição de vazão do Arroio Carahá.

Figure 3. Map of data collection points. Location of sediment samples (channel, sandy shoal, bay), linigraph (data on water levels in the Lagoa dos Patos) and flow measurement point in the Carahá Creek. 
disponibilizados no banco de dados da ANA. Em 99,1\% dos dados a precipitação total diária foi menor que $60 \mathrm{~mm}$ e em apenas 0,9\%, maior ou igual a $60 \mathrm{~mm}$. Portanto, as medições de vazão foram feitas em períodos que representam, de forma geral, 99,1\% da precipitação na Bacia Hidrográfica do Arroio Carahá.

\section{Dados de ondas}

Para reduzir o esforço computacional da modelagem morfodinâmica, foram adotados 36 cenários de ondas (Hs, Tp e Dp) como forçantes na fronteira SE da grade numérica da enseada de São Lourenço do Sul.

Os cenários de ondas foram determinados por Lemke et al. (2018) utilizando o modelo SWAN acoplado com o FLOW, validado por Lemke et al. (2017b) a partir da aferição com dados do ondógrafo direcional Waverider (adquirido pela FURG por meio do projeto Rede Ondas) fundeado no primeiro semestre de 2015 no ponto de coordenadas 412.749,08 m E e 6.516.280,54 m N, UTM 22S (Fig. 1C). Com dados de ventos do ano de 2008 (ano representativo de 2004 a 2010), os autores obtiveram 2928 cenários de ondas e reduziram para 9 casos por estação do ano, totalizando 36 cenários. A redução dos casos de ondas foi feita com base nos dados de Hs e Tp plotados em um gráfico de dispersão, onde cada eixo foi dividido em três partes, gerando 9 classes para cada estação do ano. Devido às feições morfológicas da região no entorno da enseada, as classes de Dp ficaram entre $30^{\circ} \mathrm{e}$ $210^{\circ}\left(30^{\circ}-90^{\circ}, 90^{\circ}-150^{\circ}, 150^{\circ}-210^{\circ}\right)$. Para cada classe foi selecionado o valor médio de Hs e Dp e o respectivo Tp médio. Na tabela 2 são apresentados os 36 cenários de ondas, conforme os tempos de ocorrências.

\section{Modelagem morfodinâmica}

A modelagem morfodinâmica foi realizada utilizando os módulos FLOW, MOR e SWAN acoplados, adotando os processos físicos da validação do SWAN aferido com dados do ondógrafo direcional Waverider realizada por Lemke et al. (2017b): quebra induzida pela profundidade, interações triplas não-lineares, fricção de fundo, dissipação da onda por ação do vento, refração e aumento da frequência.
Os autores obtiveram valores de inclinação quadrática média de 0,89 para $\mathrm{Hs}, 0,78$ para Tp e 0,83 para Dp, próximos ao valor 1,00, indicando uma correlação satisfatória entre dados modelados e dados medidos pelo ondógrafo.

A simulação da evolução morfodinâmica em 3D foi realizada através da grade numérica da enseada de São Lourenço do Sul, adotando 6 camadas verticais no modelo, considerando o o valor médio do $D_{50}$ das amostras de sedimentos da barra do Arroio Carahá e o valor médio do $\mathrm{D}_{50}$ das amostras de sedimentos da enseada de São Lourenço do Sul, utilizando a formulação de Van Rijn (1993) para o cálculo do transporte de sedimentos não coesivos. Para análise do transporte sedimentar foram selecionados três perfis transversais à linha de costa: na foz do arroio, na margem norte e na margem sul.

Para reduzir o tempo de processamento da modelagem, foi aplicada a técnica de aceleração morfológica (morfac - morphological aceleration factor). Para cada cenário de onda propagada na fronteira SE da grade numérica, foi calculado o fator morfac, conforme o tempo de ocorrência resultante da modelagem de ondas. Foi adotado o tempo de 720 minutos para o fator morfac igual a 1, portanto, para cada cenário de onda, foi calculado o fator morfac, de acordo com o tempo total de atuação da onda (Tab. 2).

\section{Resultados}

\section{1 Variação da linha de costa}

$\mathrm{Na}$ figura 4 são apresentados os resultados específicos dos perfis transversais com comportamento predominante de retração e de progradação da linha de costa ao longo de todo período estudado. Os únicos perfis que apresentaram o mesmo comportamento durante os dois períodos analisados (1953 - 1977 e 1977 - 2010) foram: P12, P13 e P31 (retração) e P26, P27, P28, P29, P33 e P34 (progradação). Os demais perfis apresentaram comportamento variável (retração em um período e progradação em outro) ou com variações de linha de costa menores que 1,0 m, valor determinado para o erro de amostragem. 
Tabela 2. Cenários de ondas conforme as ocorrências e os valores de fator Morfac (modificado de Lemke et al., 2018). Table 2. Wave scenarios in agreement with their occurrence and values of the Morfac factor (modified from Lemke et al., 2018).

\begin{tabular}{|c|c|c|c|c|c|c|c|c|}
\hline Cenário & $\begin{array}{c}\text { Estação } \\
\text { do ano }\end{array}$ & $\begin{array}{l}\text { Classe de } \\
\text { Dp (grau) }\end{array}$ & $\begin{array}{c}\text { Classe de } \\
\text { Hs (m) }\end{array}$ & $\begin{array}{l}\text { Hs } \\
(\mathbf{m})\end{array}$ & $\begin{array}{l}\text { Tp } \\
(\mathbf{s})\end{array}$ & $\underset{\text { (grau) }}{\text { Dp }}$ & $\begin{array}{c}\text { Tempo } \\
\text { (dia) }\end{array}$ & Morfac \\
\hline 1 & \multirow{9}{*}{ Verão } & \multirow{3}{*}{$30-90$} & $0,03-0,32$ & 0,17 & 2,04 & 61,7 & 7,3 & 14,5 \\
\hline 2 & & & $0,32-0,61$ & 0,45 & 2,87 & 76,4 & 7,5 & 15,0 \\
\hline 3 & & & $0,61-0,91$ & 0,71 & 3,36 & 78,0 & 1,9 & 3,8 \\
\hline 4 & & \multirow{3}{*}{$90-150$} & $0,02-0,36$ & 0,18 & 2,16 & 117,5 & 10,1 & 20,3 \\
\hline 5 & & & $0,36-0,69$ & 0,54 & 3,24 & 116,8 & 19,1 & 38,3 \\
\hline 6 & & & $0,69-1,03$ & 0,82 & 3,80 & 113,7 & 15,3 & 30,5 \\
\hline 7 & & \multirow{3}{*}{$150-210$} & $0,04-0,29$ & 0,18 & 2,21 & 177,6 & 6,0 & 12,0 \\
\hline 8 & & & $0,29-0,54$ & 0,38 & 2,89 & 177,0 & 6,3 & 12,5 \\
\hline 9 & & & $0,54-0,80$ & 0,64 & 3,65 & 179,4 & 1,3 & 2,5 \\
\hline 10 & \multirow{9}{*}{ Outono } & \multirow{3}{*}{$30-90$} & $0,04-0,26$ & 0,17 & 2,05 & 61,2 & 14,0 & 28,0 \\
\hline 11 & & & $0,26-0,48$ & 0,35 & 2,54 & 53,8 & 5,0 & 10,0 \\
\hline 12 & & & $0,48-0,70$ & 0,57 & 3,13 & 78,4 & 1,0 & 2,0 \\
\hline 13 & & \multirow{3}{*}{$90-150$} & $0,04-0,33$ & 0,18 & 2,12 & 116,7 & 11,1 & 22,3 \\
\hline 14 & & & $0,33-0,62$ & 0,43 & 2,99 & 119,9 & 7,3 & 14,5 \\
\hline 15 & & & $0,62-0,91$ & 0,74 & 3,75 & 127,4 & 2,6 & 5,3 \\
\hline 16 & & \multirow{3}{*}{$150-210$} & $0,04-0,42$ & 0,21 & 2,27 & 179,0 & 6,0 & 12,0 \\
\hline 17 & & & $0,42-0,79$ & 0,57 & 3,46 & 174,0 & 5,9 & 11,8 \\
\hline 18 & & & $0,79-1,17$ & 1,03 & 4,54 & 172,4 & 1,9 & 3,8 \\
\hline 19 & \multirow{9}{*}{ Inverno } & \multirow{3}{*}{$30-90$} & $0,06-0,32$ & 0,19 & 2,13 & 60,1 & 13,5 & 27,0 \\
\hline 20 & & & $0,32-0,58$ & 0,43 & 2,76 & 53,4 & 8,6 & 17,3 \\
\hline 21 & & & $0,58-0,84$ & 0,69 & 3,27 & 54,4 & 2,4 & 4,8 \\
\hline 22 & & \multirow{3}{*}{$90-150$} & $0,05-0,33$ & 0,19 & 2,16 & 119,3 & 7,9 & 15,8 \\
\hline 23 & & & $0,33-0,61$ & 0,48 & 3,08 & 119,5 & 7,0 & 14,0 \\
\hline 24 & & & $0,61-0,89$ & 0,72 & 3,68 & 121,6 & 4,1 & 8,3 \\
\hline 25 & & \multirow{3}{*}{$150-210$} & $0,05-0,37$ & 0,16 & 2,13 & 176,2 & 5,4 & 10,8 \\
\hline 26 & & & $0,37-0,69$ & 0,52 & 3,33 & 174,3 & 3,9 & 7,8 \\
\hline 27 & & & $0,69-1,00$ & 0,82 & 4,07 & 175,9 & 1,0 & 2,0 \\
\hline 28 & \multirow{9}{*}{ Primavera } & \multirow{3}{*}{$30-90$} & $0,06-0,33$ & 0,21 & 2,18 & 66,2 & 5,8 & 11,5 \\
\hline 29 & & & $0,33-0,61$ & 0,49 & 2,94 & 73,1 & 7,4 & 14,8 \\
\hline 30 & & & $0,61-0,88$ & 0,73 & 3,42 & 76,9 & 4,5 & 9,0 \\
\hline 31 & & \multirow{3}{*}{$90-150$} & $0,04-0,40$ & 0,28 & 2,48 & 113,2 & 7,5 & 15,0 \\
\hline 32 & & & $0,40-0,77$ & 0,60 & 3,39 & 119,7 & 26,8 & 53,5 \\
\hline 33 & & & $0,77-1,14$ & 0,90 & 3,93 & 111,8 & 12,1 & 24,3 \\
\hline 34 & & \multirow{3}{*}{$150-210$} & $0,05-0,38$ & 0,22 & 2,35 & 175,9 & 3,3 & 6,5 \\
\hline 35 & & & $0,38-0,71$ & 0,51 & 3,28 & 184,7 & 6,1 & 12,3 \\
\hline 36 & & & $0,71-1,05$ & 0,86 & 4,14 & 177,3 & 3,4 & 6,8 \\
\hline
\end{tabular}


Entre os dois períodos do estudo (1953 - 1977 e 1977 - 2010), as taxas médias de retração da linha de costa nos perfis P12, P13 e P31 foram de 1,5 m/ano, 0,8 m/ano e 0,2 m/ano, respectivamente; enquanto que as taxas médias de progradação ficaram em torno de 0,2 m/ano nos perfis P26, P27, P28, P29, P33 e P34.

$\mathrm{Na}$ margem ao norte da foz do Arroio Carahá, os processos de retração atingiram cerca de 79 m no perfil P12 e 41 m no perfil P13, entre 1953 e 2010, com taxa média de 1,1 m/ano entre estes dois perfis. Na margem ao sul da foz do arroio, os processos de progradação da linha de costa atingiram até $14 \mathrm{~m}$ no perfil P28, entre 1953 e 2010; sendo que nesta margem também ocorreu um processo pontual de retração no perfil P31.

\subsection{Simulação do comportamento morfodinâmico}

A obtenção, o tratamento e análise de dados hidrodinâmicos e morfológicos da região de estudo consistiram em uma etapa fundamental para a caracterização e compreensão das variáveis envolvidas na morfodinâmica da foz do Arroio Carahá.

De acordo com a batimetria gerada através da interpolação dos dados de profundidade realizada com o software Delft-3D (Fig. 5), a área de estudo pode ser caracterizada como uma região rasa, em que os máximos valores atingiram cerca de 2,8 m. Na porção sul da enseada há uma extensa área com as profundidades maiores, enquanto que na porção norte da enseada há uma região de depressão, com variação brusca na batimetria da região do entorno.

Quanto à granulometria, o valor médio do $D_{50}$ foi de 0,564 mm (areia grossa) para a enseada de São Lourenço do Sul, 1,16 mm (areia muito grossa) para a barra arenosa da foz do Arroio Carahá e 0,715 mm (areia grossa) para o canal do arroio.

Com a análise de dados de nível d'água, foi possível verificar que ocorreram significativas variações sazonais. De 1985 a 2019, os valores médios de nível d'água foram de 0,44 m no verão, 0,61 m no outono, 0,77 m no inverno e 0,67 m na primavera, e o valor da média geral foi de
0,64 m. Nas estações de outono e primavera, o nível médio foi mais próximo à média geral, apresentando pequenas variações: redução de 0,03 m no outono e aumento de 0,03 m na primavera. No entanto, nas estações de verão e inverno, as variações em torno da média geral foram mais acentuadas: redução de 0,20 m no verão e aumento de 0,13 m no inverno. Entre as estações de verão e inverno, a diferença entre as médias foi de 0,33 m.

Como a batimetria na região de estudo é rasa e considerando a formação da barra arenosa na foz do Arroio Carahá, estas variações sazonais nos valores de nível médio d'água podem influenciar significativamente nas condições de navegabilidade de pequenas embarcações no canal de acesso do arroio com a laguna.

Quanto à hidrodinâmica do canal do Arroio Carahá, no período estudado não foi possível obter a vazão através do molinete, pois, até mesmo nas condições após muita precipitação, a corrente existente não foi suficiente para girar as hélices do instrumento. Como as medições foram feitas após precipitações de até $59,7 \mathrm{~mm}$ e considerando que de 1966 a 2019 em 99,1\% dos dados a precipitação total diária foi menor que $60 \mathrm{~mm}$ na estação pluviométrica da Bacia Hidrográfica do Arroio Carahá, o valor de vazão considerado na modelagem morfodinâmica foi igual a zero, caracterizando uma situação crítica, ou seja, ausência de energia hidrodinâmica do arroio.

A partir da simulação da propagação dos 36 cenários de ondas foram geradas correntes na enseada devido ao processo de quebra das ondas. Na margem norte da enseada, foram geradas correntes para SO para todos os cenários de ondas. Na margem sul da enseada, foram geradas correntes para SO para os cenários de ondas das classes de Dp entre $30^{\circ}-90^{\circ}$ e $90^{\circ}-$ $150^{\circ}$. Com a propagação de ondas das classes de Dp entre $150^{\circ}$ e $210^{\circ}$, foram observados processos dinâmicos de: difração das ondas devido ao pontal sul, resultando em correntes para NE na margem sul; refração das ondas ao se aproximarem da região de depressão no norte da enseada, gerando correntes para SO na margem norte; convergência das correntes bidirecionais (NE e SO) na região central da enseada, foz do 


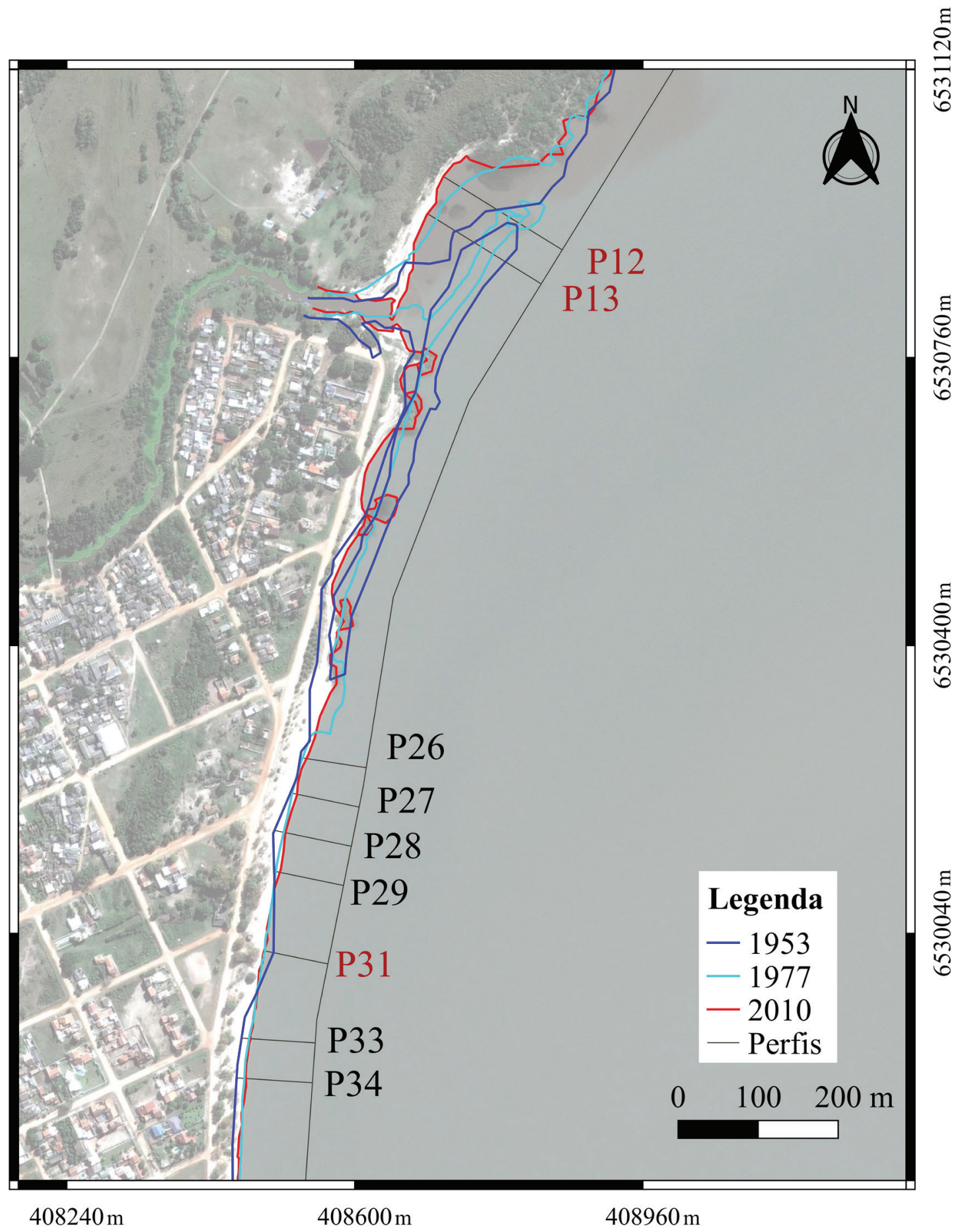

Imagem: Google Earth Pro Datum: WGS - $84 \quad$ Projeção: UTM - 22S

Figura 4. Variação temporal da linha de costa sobre a imagem de 2010 da enseada de São Lourenço do Sul. Perfis transversais que apresentaram comportamento predominante de retração (P12, P13 e P31) e de progradação da linha de costa (P26, P27, P28, P29, P33 e P34).

Figure 4. Temporal coastline variation on the 2010 image of the São Lourenço do Sul Bay. Cross profiles that exhibited predominant retraction (P12, P13 and P31) and progradation (P26, P27, P28, P29, P33 and P34) behavior on the coastline. 


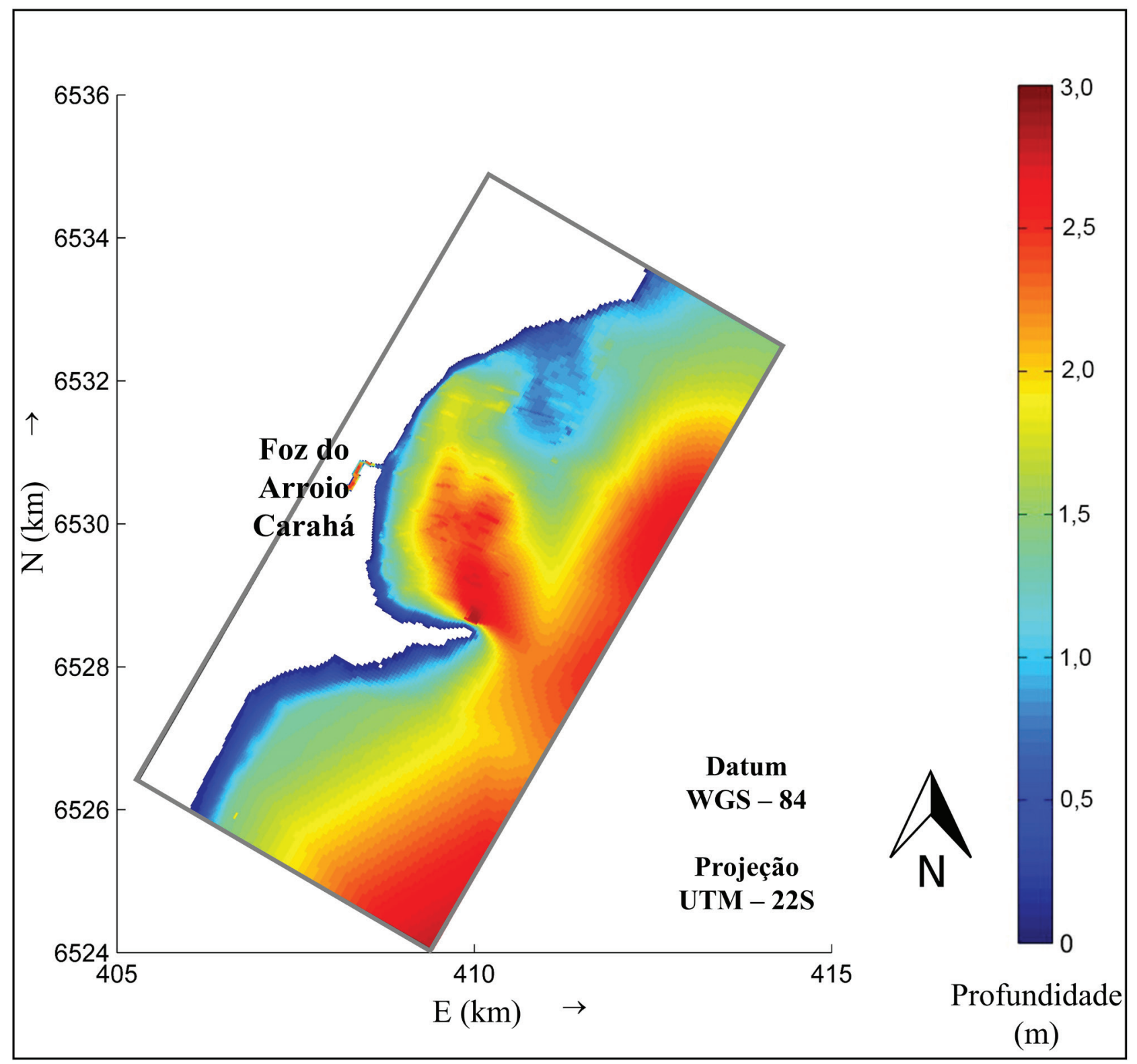

Figura 5. Batimetria obtida com a interpolação realizada na grade numérica da enseada de São Lourenço do Sul. Figure 5. Bathymetry obtained from interpolation in the numerical grid oh the São Lourenço do Sul Bay.

Arroio Carahá. Na figura 6 são apresentadas as duas situações de direção de correntes observadas na enseada: correntes somente para SO (Fig. 6A) e correntes bidirecionais (NE e SO) com a formação da zona de convergência na foz do Arroio Carahá (Fig. 6B). Como exemplos para as duas situações, são apresentadas as correntes geradas para o cenário 21 (Fig. 6A) e para o cenário 18 (Fig. 6B).

As taxas médias de transporte sedimentar obtidas com o modelo morfodinâmico, forçado com os 36 cenários de ondas e utilizando $D_{50}$ de $1,16 \mathrm{~mm}$, foram praticamente nulas ao longo de cada perfil analisado, indicando que não houve energia suficiente para mobilizar os sedimentos da classe granulométrica de areia muito grossa. Entretanto, ao utilizar $\mathrm{D}_{50}$ de $0,564 \mathrm{~mm}$, as taxas atingiram 7,3 m³/ano/m, 9 m³/ano/m e $6,7 \mathrm{~m}^{3} /$ ano/m, respectivamente, nos perfis foz, norte e sul.

Na figura 7 é apresentado um gráfico com a elevação de fundo ao longo do tempo para um ponto localizado na barra arenosa da foz do Arroio Carahá, onde se observa que, após a simulação dos 36 cenários de ondas, houve deposição de sedimentos, atingindo cerca de 0,60 m de altura. 


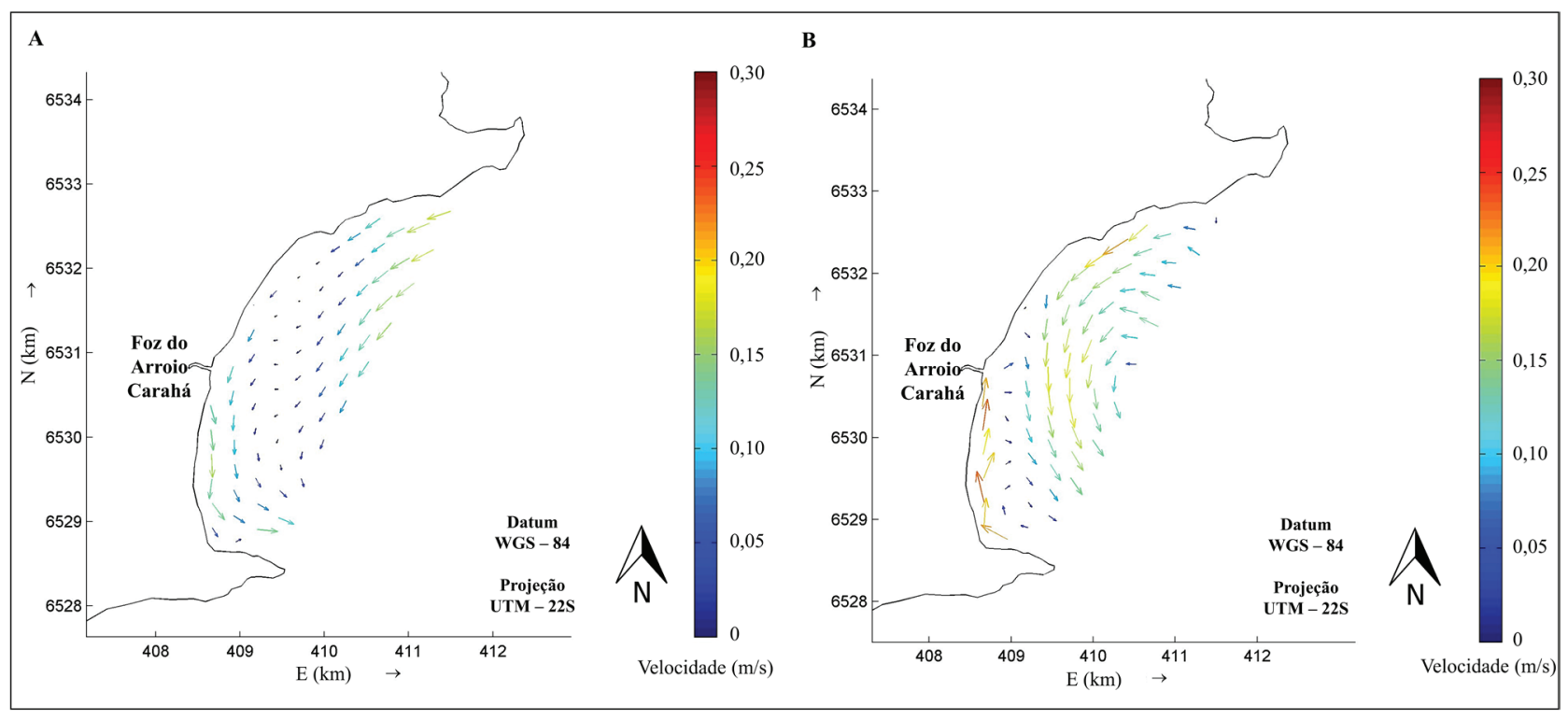

Figura 6. Direções de correntes geradas na enseada de São Lourenço do Sul. A) Correntes para SO nas margens norte e sul da enseada; B) Correntes para SO na margem norte e para NE na margem sul com a formação da zona de convergência na foz do Arroio Carahá.

Figure 6. Current directions generated in the São Lourenço do Sul Bay. A) SW currents on the northern and southern margin of the bay; B) SW currents on the northern margin and NE currents on the southern margin with the formation of the convergence zone in the mouth of the Carahá Creek.

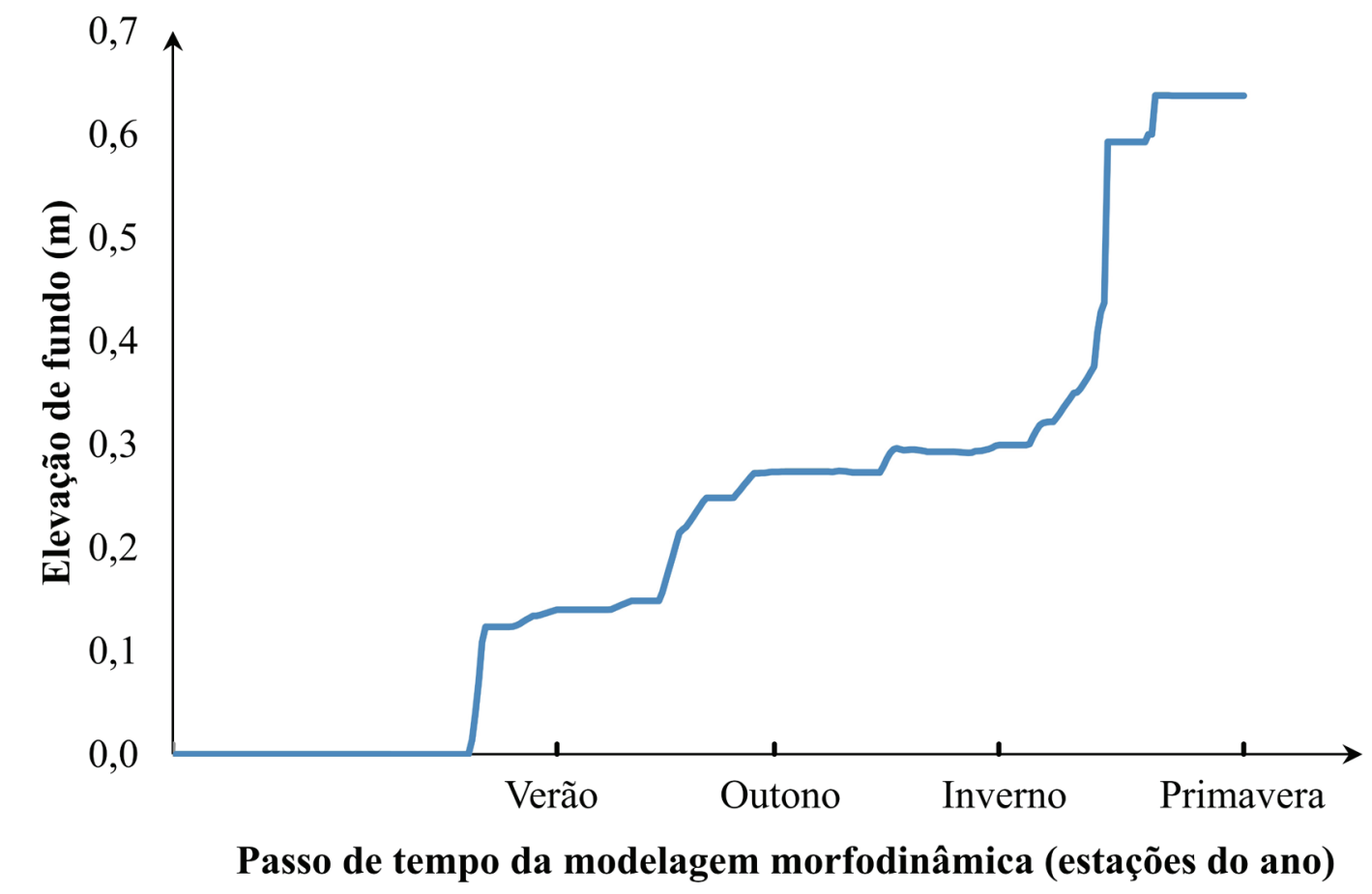

Figura 7. Elevação de fundo de um ponto na barra arenosa na foz do Arroio Carahá, de acordo com os passos de tempo da modelagem morfodinâmica para as estações do ano.

Figure 7. Bed elevation of a point on the sandy shoal in the mouth of the Carahá Creek, in agreement with morphodynamic modeling time steps in the seasons. 


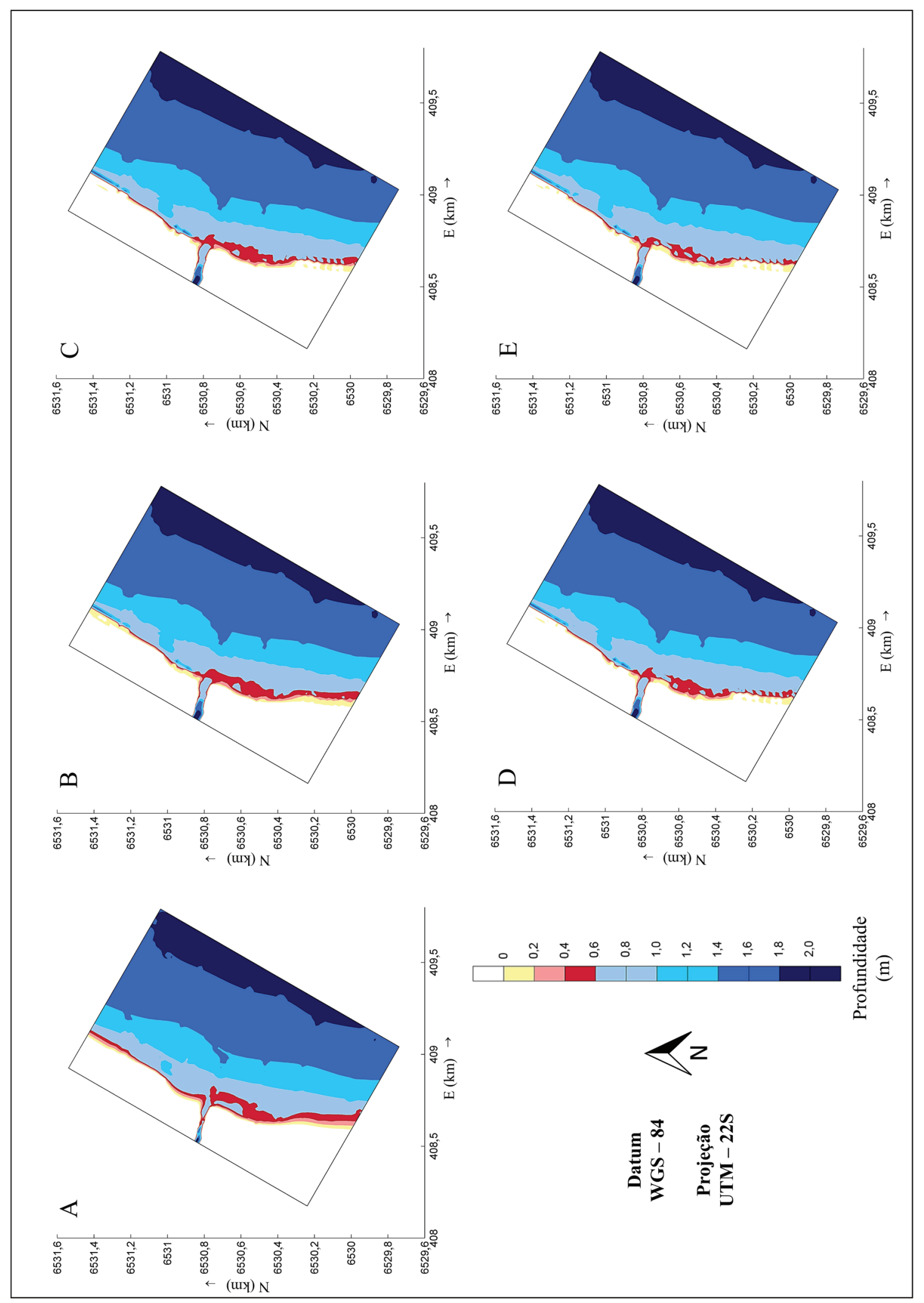

㻤

을 ह

क

范

흐응

음

\% $\frac{0}{0}$ क

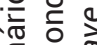

ญे ญ

क ल

ำ

ข

तथ

ह 을 है

क

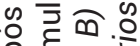

远的离

ธิธี

के

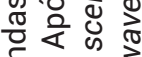

○ा

वृ के

원

京.

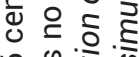

褔

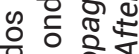

웜 인

屯ิ

बृ.

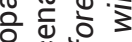

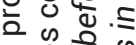

중 음 응

क \& 워 중

诘 ब

त

त) $\frac{\pi}{\omega} \cdot \frac{\pi}{\pi}$

的空范

尔为文

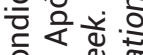

ปิ่

₹

元 윻

तु 0 \&

응

은 $\frac{0}{0}$

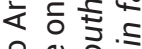

음 응 응

№ 워

징.

응 ठำ क

ङ 은응 중

웡 \& 논

일 의

을 흘 
O processo de fechamento da foz com a formação da barra arenosa pode ser visualizado na figura 8, com uma aproximação da área de interesse, onde é apresentada a condição inicial da batimetria, ou seja, antes da propagação dos 36 cenários de ondas, assim como são apresentadas as condições finais após a simulação da propagação dos cenários de ondas ao final de cada estação do ano, utilizando $D_{50}$ de 0,564 mm São apresentadas as classes de batimetria, conforme escala indicada, onde se observa que inicialmente o canal estava aberto, com profundidade entre 1,0 m e 0,6 m. Posteriormente, ao final da propagação dos cenários de ondas de verão, equivalente ao período de 74,8 dias, constata-se que ocorreu deposição de sedimentos na foz do arroio, atingindo a classe de profundidade entre 0,6 $\mathrm{m}$ e 0,4 $\mathrm{m}$, resultando no seu fechamento. No decorrer da simulação dos cenários de ondas de outono (54,8 dias), inverno (53,8 dias) e primavera (76,9 dias) observa-se que a barra arenosa permaneceu na foz do Arroio Carahá, com a mesma classe de profundidade, entre 0,6 m e 0,4 m. Ou seja, para os cenários de ondas deste estudo, após a formação da barra arenosa na foz do Arroio Carahá não foi observado processo de retirada de sedimentos que permitisse a reabertura do canal. Constatase ainda que a máxima variação entre as duas classes de profundidade $(1,0 \mathrm{~m}-0,6 \mathrm{~m}$ e 0,6 $m$ - 0,4 m) corresponde a 0,6 m, equivalente à elevação de fundo apresentada na figura 7 .

\section{Discussão dos resultados}

Conforme Toldo Jr. et al. (2003), na margem oeste da Lagoa dos Patos os sedimentos geralmente são movidos em direção à linha de costa, e a deriva litorânea é predominantemente para o sul.

De acordo com os resultados do comportamento morfodinâmico da foz do Arroio Carahá e margens adjacentes obtidos com as análises das mudanças da linha de costa e com a modelagem morfodinâmica, surge a hipótese de deriva litorânea bidirecional com predominância para o sul, retirando sedimentos da margem norte e depositando na foz do Arroio Carahá e na margem sul. Os resultados do presente estudo são comparados com estudos realizados em outras regiões da margem oeste da Lagoa dos Patos.

O comportamento da linha de costa da enseada de São Lourenço do Sul condiz com características observadas por Ambrosi (2018) para a foz do Canal São Gonçalo e região adjacente de 1953 a 2017, pois em ambos estudos foram identificados processos de retração nas margens ao norte, progradação nas margens ao sul e acumulação de sedimentos nas desembocaduras. Na enseada de São Lourenço do Sul, as taxas de retração (margem norte) e de progradação (margem sul) atingiram 1,5 m/ ano e 0,2 m/ano, respectivamente. Segundo Ambrosi (2018), as respectivas taxas foram 1,4 m/ano (margem norte) e 0,4 m/ano (margem sul) nas adjacências do Canal São Gonçalo. A autora destacou a ocorrência de ventos predominantes de NE no processo de erosão na região do Pontal da Barra (margem norte), favorecendo o transporte de sedimentos para SO, resultando na deposição sedimentar no pontal com crescimento para dentro do canal.

$\mathrm{Na}$ margem ao norte da desembocadura do Arroio Carahá, as taxas de retração média e máxima foram 1,1 m/ano e 1,5 m/ano, respectivamente, maiores que as respectivas taxas da praia do Barro Duro determinadas por Fischer \& Calliari (2011), 0,55 m/ano e 1,04 m/ ano de 1980 a 1995, e por Ferreira (2017), 0,63 m/ ano e 1,04 m/ano de 1964 a 2016. Embora a praia do Barro Duro esteja mais exposta às condições de hidrodinâmica da Lagoa dos Patos devido a sua forma mais retilínea e por estar na região do estuário, e a margem de São Lourenço do Sul esteja mais protegida por ser uma enseada, as maiores taxas de retração foram encontradas na enseada, especificamente na margem norte. Este fato pode ser atribuído à perda de vegetação nesta região, pois, segundo relatos de pescadores de São Lourenço do Sul, houve retirada de juncos na margem ao norte da foz do Arroio Carahá, fator que potencializa a erosão e que pode justificar as maiores taxas de recuo nesta praia quando comparada à praia do Barro Duro.

Fischer \& Calliari (2011) identificaram processos de progradação da linha de costa 
na praia do Laranjal com taxa de 0,21 m/ano, praticamente igual à taxa de progradação da margem ao sul da foz do Arroio Carahá, que foi de 0,2 m/ano. Segundo os autores, há existência de deriva litorânea para o sul, devido à frequente incidência oblíqua de ondas geradas por ventos de NE, explicando assim a progradação da linha de costa em alguns locais das praias estudadas; e transporte bidirecional associado a ventos de NE e SE, responsáveis pela incidência de ondas oblíquas e transporte de sedimentos para o norte.

Entre os perfis com taxas de progradação na margem ao sul da foz do Arroio Carahá, o perfil P31 apresentou taxa de retração de 0,2 $\mathrm{m} / \mathrm{ano}$. Este recuo pontual, entre processos de progradação da linha de costa, pode ser explicado pela hipótese de que antigamente poderia ter existido vegetação (juncos) semelhante a outros setores da costa em estudo. Assim, após a suposta retirada da possível vegetação, a própria dinâmica da enseada teria formado este trecho de praia mais retilíneo.

Os arcos praiais entre os esporões Dona Helena, Dona Maria e Vitoriano apresentaram comportamento predominantemente estável, conforme análise histórica de 1984 a 2013 (Miranda et al., 2019). Processos de progradação da linha de costa foram observados em regiões de desembocaduras de rios. Especificamente para o rio Graxaim, taxas de retração $(1,7 \mathrm{~m} /$ ano a $2,8 \mathrm{~m} / \mathrm{ano}$ ) ocorreram na margem direita e taxas de deposição (2,4 m/ano) na margem norte, indicando a migração da desembocadura para o sul da enseada. Segundo os autores, os arcos praiais provavelmente foram construídos pelo transporte litorâneo líquido para o sul na margem oeste da laguna, conforme Toldo Jr. et al. (2006), que relacionaram o transporte litorâneo líquido com a ação das ondas geradas pelos ventos predominantes de NE durante o verão e a primavera.

Especificamente sobre a migração da barra arenosa na foz do Arroio Carahá (Fig. 4), a qual apresentava orientação geral para NNE nos anos de 1953 e 1977, e direção aproximada para o quadrante sul no ano de 2010, surgem as seguintes hipóteses: deriva litorânea bidirecional (discutida a seguir); eventos pretéritos de elevadas vazões do arroio; e/ou ações antrópicas, com intuito de tentar estabilizar a foz para a navegação de embarcações locais. Até o momento, não há conhecimento de dados de vazão do Arroio Carahá, fato que limita a discussão da hipótese de eventos pretéritos de elevadas vazões; contudo, esta possibilidade pode ser considerada, visto que, por exemplo, eventos de intensa precipitação em curtos períodos de tempo podem ter ocorrido, possibilitando a ocorrência de significativas vazões do arroio. Quanto à hipótese de ações antrópicas, cita-se como exemplos os processos de desassoreamentos realizados através de dragagens, com a finalidade de manter a foz com um calado mínimo para o passe de embarcações.

Quanto à modelagem morfodinâmica, para a propagação dos cenários de ondas das classes de Dp entre $30^{\circ}-90^{\circ}$ e $90^{\circ}-150^{\circ}$ foram geradas correntes somente para SO na enseada. Para os cenários de ondas das classes de Dp entre $150^{\circ}$ e $210^{\circ}$ foram constatados os processos de: difração das ondas no pontal ao sul, gerando correntes para NE na margem sul; refração das ondas na região da depressão no norte da enseada, gerando correntes para SO na margem norte; formação da zona de convergência devido às correntes bidirecionais (NE e SO) na região central da enseada, foz do Arroio Carahá, com a consequente deposição de sedimentos. Miranda (2020) também identificou zonas de convergência sedimentar nos setores centrais dos arcos praias entre os esporões Dona Helena, Dona Maria e Vitoriano a partir da modelagem numérica com o Delft-3D.

As correntes geradas na margem sul da enseada foram bidirecionais (NE e SO), reforçando uma das hipóteses levantadas para o processo de migração da barra arenosa na foz. As correntes geradas na margem ao norte da foz do Arroio Carahá apresentaram direção para SO em todos os cenários simulados. Desta forma, a taxa média de transporte sedimentar utilizando $D_{50}$ de 0,564 mm foi mais acentuada no perfil ao norte da foz, atingindo cerca de $9 \mathrm{~m}^{3} / \mathrm{ano} / \mathrm{m}$, enquanto que no perfil da margem ao sul a taxa média de transporte sedimentar atingiu cerca de $6,7 \mathrm{~m}^{3} /$ ano/m. Estas taxas de transporte sedimentar corroboram com os resultados da taxa de recuo da linha de costa que foi mais proeminente na margem ao norte da foz $(1,1 \mathrm{~m} / \mathrm{ano})$ do que a 
taxa de progradação da margem ao sul $(0,2 \mathrm{~m} /$ ano), indicando um transporte sedimentar líquido para a direção sul. As direções de correntes e de transporte líquido de sedimentos do presente estudo condizem com o estudo de Miranda (2020) para os arcos praiais entre os esporões Dona Helena, Dona Maria e Vitoriano, que identificou um padrão bidirecional na deriva litorânea de sedimentos, com transporte líquido para o sul. Oliveira et al. (2018) também identificaram transporte sedimentar líquido para o sul para a praia de Arambaré a partir da constatação da gradação lateral de sedimentos (areias grossas e muito grossas no setor norte da praia, e areias médias e finas no setor sul), explicada pela direção das ondas (E e NE) responsáveis pela geração de correntes longitudinais em direção ao sul.

De acordo com os resultados do comportamento morfodinâmico para a foz do Arroio Carahá e margens adjacentes, conforme supracitado, pode-se inferir que sedimentos são retirados da margem norte da enseada e depositados na foz do Arroio Carahá e na margem sul, confirmando a hipótese de deriva litorânea predominante para o sul na enseada, corroborando com os estudos de Toldo Jr. et al. (2003), Toldo Jr. et al. (2006), Fischer \& Calliari (2011), Ferreira (2017), Ambrosi (2018), Oliveira et al. (2018), Miranda et al. (2019) e Miranda (2020).

As taxas médias de transporte sedimentar determinadas com a modelagem numérica indicam ser suficientes para realizar o processo de fechamento da foz do Arroio Carahá com a formação da barra arenosa. Após fechar a foz, as condições de baixa energia do ambiente não permitiram remobilizar os sedimentos depositados. Pode-se inferir ainda que a barra arenosa se forma na foz devido ao Arroio Carahá desembocar no ponto de convergência das correntes bidirecionais geradas com a simulação morfodinâmica.

As taxas médias de transporte sedimentar foram praticamente nulas ao utilizar $D_{50}$ de 1,16 mm na modelagem, indicando que não houve energia suficiente para mobilizar os sedimentos da classe granulométrica de areia muito grossa. Deste modo, surgem as hipóteses de que os grãos mais grossos encontrados na barra possam ser provenientes de condições de tempestades (ondas com Hs e Tp maiores que os valores dos cenários selecionados para a modelagem); eventos pretéritos com elevadas vazões do Arroio Carahá, conforme supracitado; ou ainda de um processo de winnowing, ou seja, remoção dos mais finos pelas correntes, onde permanecem os grossos (lag deposits).

A deposição sedimentar na foz do Arroio Carahá com a consequente elevação do fundo, associadas às variações do nível d'água da laguna, são processos que governam a viabilidade de navegação no local. A situação mais crítica obtida neste estudo corresponde ao caso de uma elevação de fundo em torno de 0,60 m (Fig. 7) associada ao nível médio d'água do verão, que diminui cerca de 0,20 m em relação ao nível médio geral, ou seja, a soma destes efeitos resultaria em uma variação média de 0,80 m, impedindo a navegabilidade das embarcações no local.

Conforme Bruun (1995) a estabilidade de uma desembocadura depende da energia das ondas incidentes, das correntes longitudinais e, consequentemente, do transporte litorâneo de sedimentos, assim como do fluxo do canal. Considerando que no período do estudo a vazão do Arroio Carahá foi imperceptível para o molinete utilizado e que os valores de $D_{50}$ do canal, da foz e da enseada apresentam características granulométricas diferentes, pode-se inferir que, especificamente para os dados obtidos neste estudo, a formação da barra arenosa ocorreu devido aos processos dinâmicos atuantes na enseada. Esta hipótese foi comprovada com a modelagem morfodinâmica, em que a partir da propagação das ondas de curto período e pequena altura, o processo de quebra gerou correntes responsáveis pelo transporte sedimentar litorâneo, formando a barra arenosa na zona de convergência das correntes bidirecionais (NE e SO), ou seja, na foz do Arroio Carahá. Por conseguinte, o ambiente não apresentou energia hidrodinâmica suficiente para reabrir a foz. Desta forma, o processo natural que poderá viabilizar a navegação de pequenas embarcações locais no canal está associado à variação do nível d'água 
na Lagoa dos Patos. Em períodos de muita precipitação, o nível d'água se eleva, de forma a sobrepor à crista da barra, gerando possibilidade de tornar o canal acessível para a navegação de embarcações de pequeno porte. Já em períodos em que o nível d'água está baixo e a barra arenosa está formada, torna-se impossível a passagem através do canal.

Considerando que neste estudo as taxas de transporte de sedimentos foram determinadas com a modelagem numérica a partir dos cenários representativos de ondas e que a vazão do Arroio Carahá adotada corresponde a uma situação crítica, seria interessante ter mais dados como transportes de sedimentos medidos em campo e vazão do arroio, visando ampliar as discussões deste estudo.

Destaca-se a importância e a necessidade de estudos complementares com o objetivo de propor uma solução para a comunidade local, visando manter a foz estável e com um calado mínimo para navegação de barcos pesqueiros pelo canal. Neste sentido, seria interessante a realização de estudos de modelagem morfodinâmica considerando possibilidades de intervenções antrópicas de abertura do canal através de dragagens periódicas sazonais ou anuais, assim como propostas de obras de proteção costeira para fixar a foz e manter o canal com uma profundidade mínima para embarcações locais, analisando as relações custo-benefício para as diferentes situações, de forma a propor a melhor solução para o município.

\section{Conclusões}

Este estudo permitiu identificar e compreender os processos lagunares atuantes na enseada de São Lourenço do Sul que envolvem a formação da barra arenosa na foz do Arroio Carahá e seu consequente fechamento, e quais as condições naturais que permitem o passe sobre a barra.

A partir do estudo da variação da linha de costa da enseada através das imagens aéreas georreferenciadas, pode-se concluir que durante o período analisado, 1953 a 2010, houve um acentuado processo de erosão na margem ao norte da foz do Arroio Carahá, com taxa média de 1,1 m/ano, e um processo de deposição de sedimentos ao sul da foz, com taxa média de 0,2 m/ano.

0 intenso processo erosivo na margem norte e a progradação na margem sul foram corroborados com os resultados da simulação morfodinâmica da enseada utilizando o software Delft-3D com as características granulométricas e hidrodinâmicas da região, pois para $0 D_{50}$ de 0,564 mm (areia grossa), as taxas médias de transporte de sedimentos no perfil ao norte da foz $\left(9 \mathrm{~m}^{3} / \mathrm{ano} / \mathrm{m}\right)$ foram maiores que no perfil da foz $\left(7,3 \mathrm{~m}^{3} / \mathrm{ano} / \mathrm{m}\right)$ e ao sul $\left(6,7 \mathrm{~m}^{3} / \mathrm{ano} / \mathrm{m}\right)$, apresentando predominância de transporte líquido para o sul.

Os cenários de ondas característicos da região (Hs entre 0,16 m e 1,03 m e Tp entre 2,04 s e 4,54 s) e as respectivas correntes geradas foram determinantes para a dinâmica de sedimentos da enseada. Os processos de difração das ondas devido ao pontal sul, que geraram correntes para NE na margem sul, e de refração das ondas ao se aproximarem da região de depressão no norte da enseada, que geraram correntes para SO na margem norte, foram os principais fatores responsáveis pela formação de barra arenosa na foz do Arroio Carahá devido à convergência das correntes bidirecionais (NE e SO) na região central da enseada. Além da formação da zona de convergência de correntes bidirecionais na região da foz do Arroio Carahá, outro importante processo identificado no período de estudo foi a falta de energia hidrodinâmica do arroio, impossibilitando a reabertura da foz de forma natural.

Considerando a formação da barra arenosa na foz do Arroio Carahá e a consequente elevação de fundo, o nível d'água da Lagoa dos Patos na região consiste em uma variável fundamental e determinante para condições de navegabilidade no local, pois quando o nível d'água está alto e sobrepõe significativamente a crista da barra, há possibilidade de tornar o canal acessível para pequenas embarcações locais; no entanto, quando o nível d'água está baixo, não há viabilidade de acesso. 


\section{Referências}

Ambrosi, E. 2018. Variabilidade da linha de costa na foz do Canal São Gonçalo e adjacências da Lagoa dos Patos. Rio Grande, 126p. Dissertação de Mestrado, Programa de Pósgraduação em Engenharia Oceânica, Escola de Engenharia, Universidade Federal do Rio Grande.

ANA. Agência Nacional de Águas. 2020. Dados de precipitação e de nível d'água. Disponível em: <http://www.snirh.gov.br/hidroweb/ serieshistoricas>. Acesso em: 06 jul. 2020.

Boak, E.H. \& Turner, I.L. 2005. Shoreline definition and detection: a review. Journal of Coastal Research, 21(4): 688-703.

Bruun, P. 1995. Port Engineering. Harbor transportation, fishing ports, sediment transport, geomorphology, inlets, and dredgin. Houston, Copyright, 1146p.

Camargo, M.G. 2006. SysGran: um sistema de código aberto para análises granulométricas do sedimento. Revista Brasileira de Geociências, 36(2): 371-378.

Cassiano, G.F. \& Siegle, E. 2010. Migração lateral da desembocadura do Rio Itapocú, SC, Brasil: evolução morfológica e condicionantes físicas. Revista Brasileira de Geofísica, 28(4): 537-549.

Castelão, R.M. \& Möller Jr., O.O. 2003. Sobre a circulação tridimensional forçada por ventos na Lagoa dos Patos. Atlântica, 25(2): 91-106.

DHN. Diretoria de Hidrografia e Navegação da Marinha do Brasil. Dados de batimetria. Disponível em: <https://www.marinha.mil.br/ om/diretoria-de-hidrografia-e-navegacaos. Acesso em: 24 abr. 2013.

Ferreira, N.M. 2017. Quantificação do processo erosivo e recuperação sedimentar da Praia do Barro Duro, Pelotas - RS. Rio Grande, 102p. Dissertação de Mestrado, Programa de Pósgraduação em Engenharia Oceânica, Escola de Engenharia, Universidade Federal do Rio Grande.

Fischer, A. \& Calliari, L.J. 2011. Variações morfodinâmicas das praias do "Saco do Laranjal", costa noroeste do estuário da Laguna dos Patos, RS. Pesquisas em Geociências, 38(3): 283-296.
Fitzgerald, D.M., Kraus, N.C. \& Hands, E.B. 2000. Natural mechanisms of sediment bypassing at tidal inlets. ERDC/CHL CHETN-IV-30. U.S. Army Corps of Engineers, 10p.

Goulart, E.S. \& Calliari, L.J. 2011. Morfodinâmica do banco das Três Marias - Barra do Rio Grande. Atlântica, 33(2): 123-139.

Komar, P.D. 1996. Tidal-inlet processes and morphology related to the transport of sediments. Journal of Coastal Research, 23: 23-45.

Lélis, R.J. \& Calliari, L.J. 2006. Historical shoreline changes near lagoonal and river stabilized inlets in Rio Grande do Sul state, southern Brazil. Journal of Coastal Research, 39: 301305.

Lemke, N., Calliari, L.J., Fontoura, J.A.S. \& Aguiar, D.F. 2017a. Wave directional measurement in Patos Lagoon, RS, Brazil. Revista Brasileira de Recursos Hídricos, 22(1): 1-12.

Lemke, N., Fontoura, J.A.S., Calliari, L.J., Aguiar, D.F. \& Simão C.E. 2017b. Comparative study between modeled (SWAN) and measured (waverider buoy) wave data in Patos Lagoon - RS, Brazil. Pan-American Journal of Aquatic Sciences, 12(1): 1-13.

Lemke, N., Fontoura, J.A.S., Calliari, L.J. \& Ferreira, N.M. 2018. Estimativa de cenários característicos de ondas na enseada de São Lourenço do Sul, Lagoa dos Patos - RS. Perspectivas Online: Exatas \& Engenharias, 8(20): 25-42.

Lesser, G.R., Roelvink, J.A., van Kester, J.A.T.M. \& Stelling, G. S. 2004. Development and validation of a three-dimentional morphological model. Coastal Engineering, 51(8): 883-915.

Lima, G.M.V. 2018. Estudo da variabilidade da margem do Canal do Rio Grande na raiz do Molhe Oeste (4a Secção da Barra do Rio Grande, RS). Rio Grande, 124p. Dissertação de Mestrado, Programa de Pós-graduação em Engenharia Oceânica, Escola de Engenharia, Universidade Federal do Rio Grande.

Lima, G.M.V., Fontoura, J.A.S., Lemke, N. \& Silva, M.J.B. 2019. Estimativa do transporte sedimentar induzido por ondas de norte na porção sul da margem oeste do canal deacesso ao Porto do Rio Grande (4ª Secção da Barra do Rio Grande, RS). Revista Interdisciplinar de 
Pesquisa em Engenharia, 5(1), 177-185.

Marinho, C., Arigony-Neto, J., Nicolodi, J.L., Lemke, N. \& Fontoura, J.A.S. 2020. Wave regime characterization in the northern sector of Patos Lagoon, Rio Grande do Sul, Brazil. Ocean and Coastal Research, 68: 1-18.

Martins, I.R., Villwock, J.A., Martins, L.R. \& Bemvenuti, C.E. 1989. The Lagoa dos Patos estuarine ecosystem (RS, Brazil). Pesquisas em Geociências, 22(22): 5-44.

Miranda, I.M., Toldo Jr., E.E., Klein, A.H.F. \& Silva, G.V. 2019. Shoreline evolution of lagoon sandy spits and adjacent beaches, Lagoa dos Patos, Brazil. Journal of Coastal Research, 35(5): 1010-1023.

Miranda, I.M., Toldo Jr., E. E., Klein, A.H.F., Strauss, D. \& Silva, G.V. 2020. The role of cuspate spits on wave attenuation and energy redistribution in a coastal lagoon, Lagoa dos Patos, Brazil. Geo-Marine Letters, 40: 1069-1086.

Miranda, I. M. 2020. Morfodinâmica de esporões arenosos lagunares cuspidados, Lagoa dos Patos, Brasil. Porto Alegre, 173p. Tese de Doutorado, Programa de Pós-graduação em Geociências, Instituto de Geociências, Universidade Federal do Rio Grande do Sul.

Möller Jr., O.O., Lorenzzentti, J.A., Stech, J. \& Mata, M.M. 1996. The Patos Lagoon summertime circulation and dynamics. Continental Shelf Research, 16(3): 335-351.

Möller Jr., O.O., Castaing, P., Salomon, J.C. \& Lazure, P. 2001. The influence of local and nonlocal forcing effects on the subtidal circulation of Patos Lagoon. Estuaries, 24(2): 297-311.

Oliveira, E.B., Nicolodi, J.L., Marinho, C., Machado Jr., V.C. 2018. Caracterização sedimentológica da praia de Arambaré, Laguna dos Patos, Rio Grande do Sul, Brasil. Revista Brasileira de Geomorfologia, 19(4): 665-678.

Santos, I., Fill, H.D., Sugai, M.R.V.B., Buba, H., Kishi, R.T., Marone, E. \& Lautert, L.F. 2001. Hidrometria aplicada. Curitiba, CEHPAR, 372p.
Simão, C.E. 2016. Estudo do padrão de ondulações na Lagoa dos Patos utilizando o modelo SWAN (DELFT3D), RS, Brasil. Rio Grande, 89p. Dissertação de Mestrado, Programa de Pósgraduação em Engenharia Oceânica, Escola de Engenharia, Universidade Federal do Rio Grande.

Suguio, K. 1973. Introdução a sedimentologia. São Paulo, Edgard Blücher - EDUSP, 317p.

Toldo Jr., E.E. 1991. Morfodinâmica da Laguna dos Patos, Rio Grande do Sul. Pesquisas em Geociências, 18(1): 58-63.

Toldo Jr., E.E., Almeida, L.E.S.B. \& Corrêa, I.C.S. 2003. Forecasting shoreline changes of Lagoa dos Patos lagoon, Brazil. Journal of Coastal Research, 35: 43-50.

Toldo Jr., E.E., Almeida, L.E.S.B., Corrêa, I.C.S., Ferreira, E.R. \& Gruber, N.L.S. 2006. Wave prediction along Lagoa dos Patos coastline, southern Brazil. Atlântica, 28(2): 87-95.

Vinzon, S.B., Winterwerp, J.C, Nogueira, R. \& de Boer, G.J. 2009. Mud deposit formation on the open coast of the larger Patos LagoonCassino Beach system. Continental Shelf Research, 29(3): 572-588.

Zencovitch, V.P. 1959. On the genesis of cuspate spits along lagoon shores. Journal of Geology, 67: 267-277. 